\title{
Maternal near Miss- Is it just a Terminology?
}

\author{
Dr. Mridula Singh ${ }^{1}$, Dr. Swati Solanki ${ }^{*}$ \\ ${ }^{1}$ Assistant Professor, Department of Obstetrics and Gynaecology, Atal Bihari Vajpayee Government Medical College, Vidisha, Madhya Pradesh, India \\ ${ }^{2}$ Senior resident, Department of Obstetrics and Gynaecology, Atal Bihari Vajpayee Government Medical College, Vidisha, Madhya Pradesh, India
}

*Corresponding author: Dr. Swati Solanki

\section{Abstract}

Introduction: Although maternal mortality remains a public health issue, maternal death in actual number is less in community. As maternal death in itself is not sufficient to assess the level of health care concept of Near miss is introduced by WHO, though yet not widely adapted in reviews across our nation and being overcome by wide variety of high risk pregnancies. Objective: To determine frequency and nature of near miss events among pregnant women. 2 . To compare nature of near miss pregnancies with high risk pregnancies. Methodology: A Case Control study of cases of near miss and high risk pregnancies which occurred over one year duration between $1^{\text {st }}$ July 2018 to $30^{\text {th }}$ June 2019 at Atal Bihari Vajpayee Govt. Medical College, Vidisha (M.P.). Near Miss definition was based on validated disease specific criteria comprising of diagnostic categories: haemorrhage, hypertensive disorder of pregnancy, anemia, sepsis, hepatic encephalopathy and other indirect causes. Near miss cases were determined for various disease processes and compared with high risk cases to assess the need for change in approaching these pregnancies. Result: There were 5993 deliveries and 7 maternal deaths. Significant difference was observed in characteristics of near miss and high risk pregnancies. Conclusion: Our review shows that beside the women who died due to pregnancy related complication, there were many additional women who received critical care during the same period and survived. Hospitals in India could benefit by including near miss investigations in their approach to all high risk pregnancies.

Keywords: Near- miss, maternal near-miss, maternal mortality, severe acute maternal morbidity, SAMM.

Copyright @ 2020: This is an open-access article distributed under the terms of the Creative Commons Attribution license which permits unrestricted use, distribution, and reproduction in any medium for non-commercial use (NonCommercial, or CC-BY-NC) provided the original author and source are credited.

\section{INTRODUCTION}

Although maternal mortality remains a public health issue, maternal death in actual number is less in community to assess and analyse the level of health care for which concept of Near miss was introduced by WHO[1]. It offers larger number of cases, greater acceptability as death has not occurred and opportunity of interaction with the women themselves.

INTERNATIONAL SCENARIO- In 2009, WHO established standard criteria for identification of women presenting pregnancy-related life-threatening conditions[2], with the goal to enable a common ground for identification across countries and to allow international comparison to be carried out.

INDIAN SCENARIO- WHO near miss criteria in Indian setting is yet not widely adapted in reviews across our nation and is being overcome by wide variety of high risk pregnancies.
High risk criteria instead of near miss criteria is the indicator which is being considered in calculating national data and making plans for improving maternal health care. High risk criteria lead to study of larger portion, often leading to difficulty in monitoring the actual trend of severe maternal morbidity.

Hence this study to try to see applicability of WHO Near miss tool in low-resource Indian setting and to find out in which cases High risk criteria is selfsufficient.

\section{OBJECTIVE OF THE STUDY}

- To determine frequency and nature of near-miss events among pregnant women.

- To compare nature of near-miss pregnancy with high risk pregnancy. 


\section{METHODS}

Type of studyDuration of study-

Comparative study

Time period-

Place of study-

College, Vidisha.

Near miss definition based on validated disease specific criteria comprised of diagnostic categories haemorrhage, hypertensive disorders in pregnancy, anaemia, sepsis, early pregnancy complications and others.

Near miss were determined for various disease process and compared with High risk cases to assess the need for change in approaching these pregnancy

\section{Inclusion Criteria}

- All women who were admitted for obstetric cause.

- Women who had no life threatening condition unrelated to pregnancy.

\section{Exclusion Criteria}

- Maternal death

- Women lost to follow up.

\section{Data Analysis}

Data was entered in excel sheet and was calculated for frequency and percentage. Association between the variables was established using EPI info software using chi-square test.

P-value $<0.05$ was considered to be a significant difference and $<0.005$ was considered to be highly significant.

\section{RESULTS}

Out of 5993 admitted women, near miss was 6\% (327 women) and High risk was 36.7\% (1998 women).

Higher age group (>35 years) formed $20 \%(\mathrm{n}=$ 40 women) of High risk cases, yet only $6.7 \%(n=22$ women) of Near miss cases belonged to this age group. This difference was significant (Chi sq. 40.05, p value $<0.05$ ) (Table-1).

Majority of women in both the groups belonged to BG Prasad Scale IV or V with $76 \%$ ( $n=$ 249 women) and $70 \%$ ( $n=1399$ women) of Near miss and High risk groups respectively. This difference was not significant (Chi sq. 12.79, p value- 0.12) (Table-2).
As the education level increased High risk cases decreased but Near miss cases decreased even further. $9.1 \% \quad(n=30 \quad$ women $)$ and $21.4 \% \quad(n=428$ women) of Near miss cases and High risk cases had education level of $12^{\text {th }}$ pass or above. (Chi sq. 38.39, p value $<0.05)($ Table-3).

$67.88 \%(\mathrm{n}=222$ women $)$ and $72.9 \%(\mathrm{n}=1458$ women) of Near miss and High risk cases respectively lived in rural area. This difference was not significant (Chi sq. 3.67, p value- 0.057). (Table-4).

$68.19 \%(n=223$ women $)$ and $71.22 \%(n=1423$ women) of Near miss and High risk cases respectively had parity of 2-3. This difference was not significant (Chi sq. 3.074, p value- 0.2150) (Table-5).

$73.7 \%(n=241$ women $)$ and $64.1 \% \quad(n=1279$ women) of Near miss and High risk cases respectively were referred cases. This difference was not significant (Chi sq. 11.65, p value> 0.05) (Table-6).

Though only $14 \%$ ( $\mathrm{n}=280$ women $)$ of High risk cases were already booked, Near miss had just $3 \%$ ( $\mathrm{n}=10$ women) Booking ratio i.e. booked High risk cases did fairly well. This difference was significant (Chi sq. 30.9, p value< 0.05) $($ Table-7).

Near miss cases due to Post-partum Haemorrhage, hypertensive disorder of pregnancy, early pregnancy complication and anaemia were $36.69 \%$ ( $\mathrm{n}=120$ women), $32.72 \%$ ( $\mathrm{n}=107$ women), $12.8 \%$ ( $\mathrm{n}=42$ women) and $21.71 \% \quad(\mathrm{n}=71$ women $)$ respectively compared to $25.57 \% \quad(\mathrm{n}=511$ women), $24.20 \%$ ( $\mathrm{n}=484$ women), $6.8 \% \quad(\mathrm{n}=136$ women $)$ and $35.98 \%$ ( $\mathrm{n}=719$ women) respectively of High risk cases. For all these major causes of maternal morbidity $\mathrm{p}$ value was $<0.005$ and difference was highly significant suggesting that High risk criteria stands not useful and fails as a helping tool (Table-8).

Near miss cases due to Ante partum Haemorrhage, Sepsis and other causes were $11.92 \%$ ( $\mathrm{n}=39$ women), $22.93 \%(\mathrm{n}=75$ women $)$ and $11.92 \%$ $(\mathrm{n}=39$ women) respectively compared to $13.31 \%$ ( $\mathrm{n}=266$ women), $26.97 \%(\mathrm{n}=539$ women) and $12.56 \%$ ( $\mathrm{n}=251$ women) respectively of High risk cases. For all these major causes of maternal morbidity $\mathrm{p}$ value was $>0.05$ and difference was not significant suggesting that High risk criteria may remain useful as a preliminary step to select potentially severe cases mainly those related to APH, Sepsis and Other causes (Table-8).

Table-1: Distribution according to age

\begin{tabular}{|l|l|l|l|l|}
\hline AGE (years) & NM (n) & \% & HR (n) & \% \\
\hline$<25$ & 88 & 26.9 & 359 & 17.96 \\
\hline $25-35$ & 217 & 66.37 & 1238 & 61.96 \\
\hline$>35$ & 22 & 6.73 & 401 & 20.07 \\
\hline TOTAL & 327 & & 1998 & \\
\hline
\end{tabular}


Table-2: Distribution according to SOCIO ECONOMIC STATUS

\begin{tabular}{|l|l|l|l|l|}
\hline BG PRASAD SCALE & NM (n) & \% & HR (n) & \% \\
\hline I & 10 & 3.05 & 41 & 2.05 \\
\hline II & 29 & 8.86 & 159 & 7.9 \\
\hline III & 39 & 11.9 & 399 & 19.97 \\
\hline IV & 112 & 34.25 & 623 & 31.2 \\
\hline V & 137 & 41.89 & 776 & 38.8 \\
\hline TOTAL & 327 & & 1998 & \\
\hline
\end{tabular}

Table-3: Distribution according to education level

\begin{tabular}{|l|l|l|l|l|}
\hline EDUCATION & NM & \% & HR & \% \\
\hline${\text { Illiterate } \&<5^{\text {th }}}^{\text {th }}$ & 104 & 31.8 & 557 & 27.8 \\
\hline $5^{\text {to } 12^{\text {th }}}$ & 193 & 59.02 & 1013 & 50.7 \\
\hline $12^{\text {th }}$ pass & 21 & 6.4 & 236 & 11.8 \\
\hline Graduate/ PG & 9 & 2.7 & 192 & 9.6 \\
\hline TOTAL & 327 & & 1998 & \\
\hline
\end{tabular}

Table-4: Distribution according to living area

\begin{tabular}{|l|l|l|l|l|}
\hline & NM (n) & \% & HR (n) & \% \\
\hline RURAL & 222 & 67.88 & 1458 & 72.9 \\
\hline URBAN & 105 & 32.12 & 540 & 27.02 \\
\hline total & 327 & & 1998 & \\
\hline
\end{tabular}

Table-5: Distribution according to Parity

\begin{tabular}{|l|l|l|l|l|}
\hline PARITY & NM (n) & \% & HR (n) & \% \\
\hline PRIMI & 65 & 19.8 & 332 & 16.61 \\
\hline $2-3$ & 223 & 68.19 & 1423 & 71.22 \\
\hline$>=4$ & 39 & 11.9 & 243 & 12.16 \\
\hline TOTAL & 327 & & 1998 & \\
\hline
\end{tabular}

Table-6: Distribution according to referral status

\begin{tabular}{|l|l|l|l|l|}
\hline & NM(n) & \% & HR(n) & \% \\
\hline Referred & 241 & 73.7 & 1279 & 64.01 \\
\hline Unreferred & 86 & 26.3 & 719 & 35.99 \\
\hline TOTAL & 327 & & 1998 & \\
\hline
\end{tabular}

Table-7: Distribution according to booking status

\begin{tabular}{|l|l|l|l|l|}
\hline & NM(n) & \% & HR(n) & \% \\
\hline UNBOOKED & 317 & 96.94 & 1718 & 85.9 \\
\hline BOOKED & 10 & 3.05 & 280 & 14.0 \\
\hline TOTAL & 327 & & 1998 & \\
\hline
\end{tabular}

Table-8: Spectrum of morbidities

\begin{tabular}{|l|l|l|l|l|l|l|}
\hline & NM(n) & $\%$ & HR (n) & $\%$ & Chi-Sq & p value \\
\hline 1. PPH & 120 & 36.69 & 511 & 25.57 & 17.58 & $<\mathbf{0 . 0 0 0 0 1 3}$ \\
\hline 2. Hypertensive disorder of preg. & 107 & 32.72 & 484 & 24.20 & 10.7 & $<\mathbf{0 . 0 0 0 5 3}$ \\
\hline 3.APH & 39 & 11.92 & 266 & 13.31 & 0.474 & $<0.2455$ \\
\hline 4. Early pregnancy complication & 42 & 12.8 & 136 & 6.80 & 14.99 & $<\mathbf{0 . 0 0 0 0 7}$ \\
\hline 5. Sepsis & 75 & 22.93 & 539 & 26.97 & 0.87 & $<0.174$ \\
\hline 6. Anemia & 71 & 21.71 & 719 & $\mathbf{3 5 . 9 8}$ & 25.52 & $<\mathbf{0 . 0 0 0 8 1}$ \\
\hline 7. Other & 39 & 11.92 & 251 & 12.56 & 0.1041 & $<0.373$ \\
\hline
\end{tabular}

\section{DISCUSSION}

In a study by Roopa et al. Manipal amongst leading causes of near-miss were severe haemorrhage, hypertensive disorders of pregnancy and sepsis, which is similar to our study result with $36.69 \%, 32.27 \%$ and $22.93 \%$ respectively. They had taken WHO 2009 criteria for inclusion criteria of near-miss cases [3].
Similarly in the study by Saima Aziz Siddiqui et al. from Pakistan, they used disease-specific criteria by Waterstone et al. and haemorrhage was the leading cause, followed by hypertensive disorders as it is in our study with $36.69 \%$ followed by $32.27 \%$ respectively [4]. 
Similarly in the study by Wanchai Wianwiset M.D., in Thailand, he used WHO criteria of 2009 for near-miss cases. Amongst the causes of near-miss cases, hypertension $(44.7 \%)$ and obstetric haemorrhage were the leading causes, whereas hypertension, embolism, haemorrhage and infection were the leading causes of maternal death [5].

\section{CONCLUSION}

Following WHO guidelines of identifying near miss has resulted in detecting the truly severe cases and is a more efficient segregating tool than identifying high risk cases. Moreover high risk criteria may give a sense of false threat or false security in many.

\section{LIMITATION}

This is a Hospital Based Study so the results cannot be generalized among general population

\section{ACKNOWLEDGEMENTS}

We would like to thank Dr. Akanksha Jain for statistical support and Dr. Veerendra Singh for technical guidance.

\section{REFERENCES}

1. World Health Organization. (2011). Evaluating the quality of care for severe pregnancy complications: the WHO near-miss approach for maternal health.

2. Say, L., Souza, J. P., \& Pattinson, R. C. (2009). Maternal near miss-towards a standard tool for monitoring quality of maternal health care. Best practice \& research Clinical obstetrics \& gynaecology, 23(3), 287-296.

3. Ps, R., Verma, S., Rai, L., Kumar, P., Pai, M. V., \& Shetty, J. (2013). "Near miss" obstetric events and maternal deaths in a tertiary care hospital: an audit. Journal of pregnancy, 2013.

4. Siddiqui, S. A., Soomro, N., \& Hasnain, F. S. (2012). Severe obstetric morbidity and its outcome in patients presenting in a tertiary care hospital of Karachi. JPMA-Journal of the Pakistan Medical Association, 62(3), 226.

5. Wianwiset, W. (2012). Maternal near miss (severe morbidity) at Sisaket Hospital. Thai Journal of Obstetrics and Gynaecology, 69-76. 